\title{
Albendazole-induced anagen effluvium: a brief literature review and our own experience
}

\author{
Çağrı Turan ${ }^{1 凶}$, Nurcan Metin ${ }^{1}$ \\ ${ }^{1}$ Department of Dermatology and Venereology, University of Health Sciences, Erzurum Regional Training and Research Hospital, Erzurum, Turkey.
}

\begin{abstract}
Albendazole is a drug commonly used for treating many parasitoses. The primary mechanism of action is inhibition of microtubule polymerization binding to $\beta$-tubulin, similar to colchicine as a microtubule formation inhibitor. It is reasonable that these two antimitotic drugs can cause side effects such as alopecia and cytopenia by a similar mechanism. In the literature, only one albendazole-induced anagen effluvium has been reported. This article presents two cases of anagen effluvium that developed 2 weeks after oral albendazole administration, summarizes all cases reported to date, and offers recommendations for a diagnostic approach.
\end{abstract}

Keywords: albendazole, anagen effluvium, alopecia, drug-induced, hair loss, medication-induced, noncicatricial alopecia, parasite, side effect, toxicity

Received: 6 May 2020 | Returned for modification: 1 June 2020 | Accepted: 30 June 2020

\section{Introduction}

Albendazole is a broad-spectrum antiparasitic drug that has been used for 42 years. Although it is generally well tolerated, rare side effects such as alopecia and cytopenia have been reported (1-3). In a study of the effect of albendazole on microsomal enzymes by Steiger et al., long-term albendazole treatment ( 600 mg/day for 4 weeks) was administered to 12 adult patients with hydatid cysts. It was reported that major side effects such as hepatotoxicity ( $n$ $=1)$, neutropenia $(n=2)$, and sudden-onset alopecia $(n=1)$ developed. The case of alopecia was accompanied by neutropenia, and the alopecia started to improve within 3 weeks after discontinuation of the drug. However, on further questioning, six of the 12 patients reported hair loss during albendazole courses (2). In another study, it was reported that one of 16 patients that received albendazole at a dose of $10 \mathrm{mg} / \mathrm{kg} /$ day for 28 days experienced reversible total alopecia (3). It is noteworthy that, in many cases, a diagnostic approach to hair loss has not been established, and there is no hypothesis about its pathogenesis.

\section{Case 1}

A 39-year-old female patient presented with complaints of excessive hair loss, which had developed rapidly about 1.5 months earlier. There was no known additional systemic disease, lactation, febrile disease, drug usage except albendazole, or trauma in her personal history. The patient had used oral albendazole at $1,200 \mathrm{mg} /$ day (14 mg/kg/day) for 21 days for treatment of Taenia saginata 2 months previously. The patient had begun to complain after the second week of high-dose albendazole therapy. There was a diffuse alopecia appearance with a few short hairs in the dermatological examination of the patient (Fig. 1a). There was no erythema, crust, or atrophy, and a scar was observed on the scalp. The pull test was positive. Body hairs were in normal distribution and frequency. Upon trichoscopic examination, there was no evidence of yellow dots or exclamation-mark hairs. In laboratory studies, hemogram, serum iron, ferritin, folic acid, vitamin B12, zinc levels, renal function tests, and thyroid-stimulating hormone were within normal ranges. The patient had ALT $82 \mathrm{U} / 1$ (o-35 U/l), AST 70 U/1 (o-35 U/1), ALP 641 U/1 (o-35 U/1), GGT 46 U/1 (o-38 $\mathrm{U} / \mathrm{l})$, and indirect bilirubin $1.12 \mathrm{mg} / \mathrm{dl}(\mathrm{o}-1.0 \mathrm{mg} / \mathrm{dl})$, which was seen 1 month after the discontinuation of the drug even though baseline liver function tests (LFT) were not observed. HepatitisHIV-syphilis serology and ANA tests were negative. Toxic hepatitis was considered in the patient with normal hepatobiliary ultrasonography. The LFT values examined every 2 weeks decreased gradually and fell to a normal level after 1 month. Two $4 \mathrm{~mm}$ scalp punch biopsies were examined using vertical and horizontal sectioning. In histopathological examination, vellus hairs were less than $0.03 \mathrm{~mm}$, and terminal shafts were larger than $0.06 \mathrm{~mm}$. Anagen follicles were observed in all areas, without perifollicular lymphocytic infiltration, and no telogen follicles were found. Histopathological findings were compatible with anagen effluvium (AE) (Fig. 2). The patient, who had hair re-growth after the second week of follow-up without any treatment, is shown in Figure $1 \mathrm{~b}$ after 3 months.

\section{Case 2}

A 9-year-old girl, who was evaluated at our clinic with a diffuse hair loss complaint that started a month previously, had used albendazole at a dose of $400 \mathrm{mg} /$ day ( $14 \mathrm{mg} / \mathrm{kg} /$ day) for 3 days about 6 weeks earlier due to Enterobius vermicularis. It was learned that her complaints emerged quickly within 2 weeks of albendazole use, and her current state was better than previously. Before this, the patient had not had similar complaints, any other diseases, regular medications, surgery, hospitalization history, diet, or any other physical or psychological stress factors. The dermatological examination showed a diffuse reduction in hair density and various lengths of hairs, not accompanied by erythema, squam, atrophy, or scarring (Fig. 1c). There was no shedding of body hair. The hair pull test was positive. No yellow dot or exclamation mark 

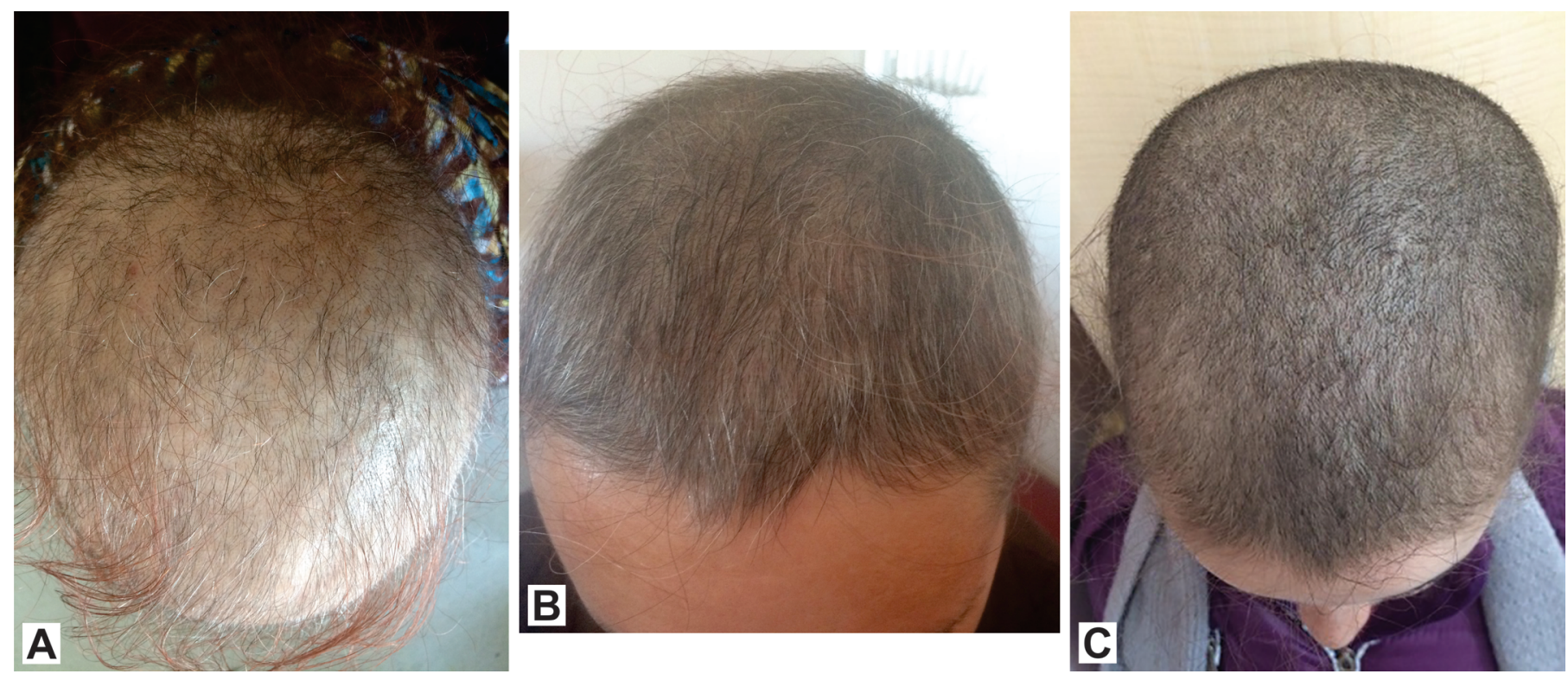

Figure 1 | a) Diffuse alopecia of the scalp with a few short hairs, b) hair regrowth after 3 months, c) diffuse alopecia with short hair in the first presentation.

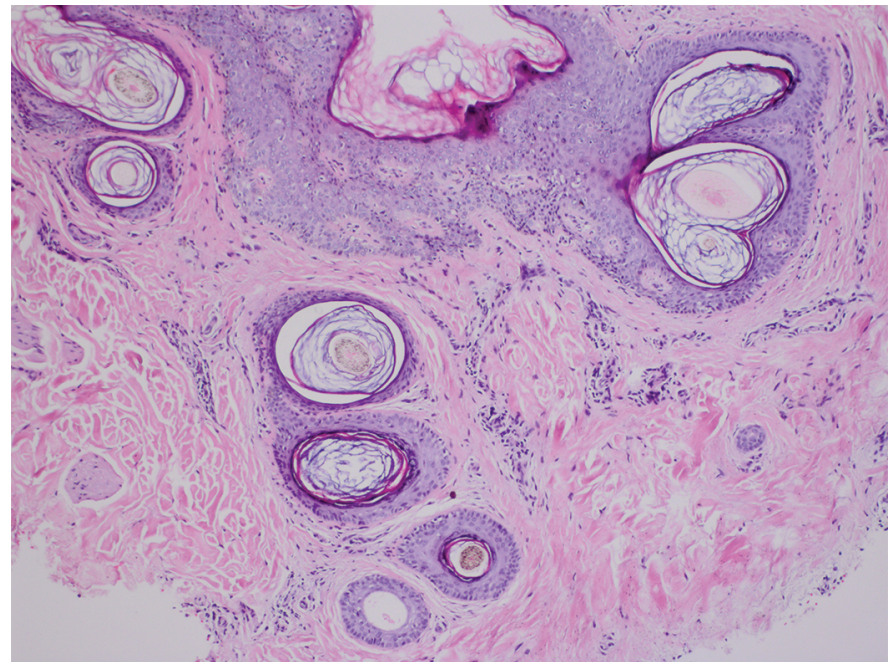

Figure 2 | H\&E staining $(\times 200)$ showing anagen follicles in all areas without perifollicular lymphocytic infiltration.

Table 1 | Patients with albendazole-induced alopecia to date.

\begin{tabular}{|c|c|c|c|c|c|c|}
\hline $\begin{array}{l}\text { Reference no. } \\
\text { (year) }\end{array}$ & $\begin{array}{c}\text { Age (years), } \\
\text { sex }\end{array}$ & Albendazole dose (time) & Presentation & Diagnosis & $\begin{array}{l}\text { Onset of } \\
\text { alopecia }\end{array}$ & $\begin{array}{c}\text { Recovery } \\
\text { time*t }\end{array}$ \\
\hline $2(1990)$ & $35, F$ & $\begin{array}{l}8 \mathrm{mg} / \mathrm{kg} / \text { day }(1 \text { week }) \\
\text { for hydatid cyst }\end{array}$ & $\begin{array}{l}\text { Subtotal diffuse alopecia } \\
\text { and neutropenia }\end{array}$ & $?$ & 1st week & 3 weeks \\
\hline 17 (1990) & $59, \mathrm{~F}$ & $\begin{array}{l}400 \mathrm{mg} / \text { day ( } 4 \text { weeks) } \\
\text { for hydatid cyst }\end{array}$ & Sudden-onset diffuse alopecia & TE & After 1 month & 1 month \\
\hline 18 (1992) & $30, \mathrm{~F}$ & $\begin{array}{c}10-12 \mathrm{mg} / \mathrm{kg} / \mathrm{day} \text { (51 days) } \\
\text { for hydatid cyst }\end{array}$ & Diffuse alopecia + neutropenia & $?$ & After 1 month & $?$ \\
\hline $9(2012)$ & $70, M$ & $\begin{array}{l}15 \mathrm{mg} / \mathrm{kg} / \text { day ( } 20 \text { days) } \\
\text { for hydatid cyst }\end{array}$ & $\begin{array}{l}\text { Total diffuse alopecia and total } \\
\text { body hair loss }\end{array}$ & $?$ & 20th day & 1 month \\
\hline 19 (2012) & $25, F$ & $\begin{array}{c}400 \mathrm{mg} / \text { day (1 week, } 2 \text { courses) } \\
\text { cutaneous larva migrans }\end{array}$ & Diffuse alopecia & TE & Second course & 3 months \\
\hline 6 (2019) & $74, F$ & $\begin{array}{l}800 \mathrm{mg} / \text { day ( } 5 \text { days) } \\
\text { for Toxocara }\end{array}$ & $\begin{array}{l}\text { Sudden-onset diffuse alopecia } \\
\text { and total body hair loss }\end{array}$ & $\mathrm{AE}$ & After 2 weeks & $?$ \\
\hline $20(2020)$ & $53, M$ & $\begin{array}{l}113.6 \mathrm{~g} \text {, total cumulative dose; } \\
\text { two bottles of veterinary-grade } \\
\text { albendazole ( } 3 \text { weeks) for } \\
\text { delusional parasitosis }\end{array}$ & $\begin{array}{l}\text { Diffuse alopecia, pancytopenia, } \\
\text { hepatotoxicity, and } \\
\text { hyperpigmentation } \\
\text { along the jaw line }\end{array}$ & $?$ & After 2 weeks & $? \ddagger$ \\
\hline \multirow[t]{2}{*}{ This report } & $39, F$ & $\begin{array}{c}14 \mathrm{mg} / \mathrm{kg} / \text { day }(21 \text { days) for } \\
\text { Taenia saginata }\end{array}$ & $\begin{array}{l}\text { Sudden-onset diffuse alopecia } \\
\text { and hepatotoxicity }\end{array}$ & $\mathrm{AE}$ & After 2 weeks & 2 months \\
\hline & $9, \mathrm{~F}$ & $\begin{array}{l}14 \mathrm{mg} / \mathrm{kg} / \text { day ( } 3 \text { days) for } \\
\text { Enterobius vermicularis }\end{array}$ & Sudden-onset diffuse alopecia & $\mathrm{AE}$ & After 2 weeks & 1 months \\
\hline
\end{tabular}

$\mathrm{F}=$ female, $\mathrm{M}=$ male $\mathrm{TE}=$ telogen effluvium, $\mathrm{AE}=$ anagen effluvium.

*time after drug discontinuation, tall cases achieved remission during follow-up without treatment, ‡recovered with supportive therapy. was found in trichoscopy. There was no diameter difference in the hair shafts. All laboratory tests were within normal limits. Considering our previous experience related to albendazole and the patient's typical history, the patient was evaluated as having albendazole-induced $\mathrm{AE}$, and her complaints improved over time without any medication.

\section{Discussion}

Albendazole is a benzimidazole derivative, especially used in the treatment of hydatid cysts and many other parasitoses (4). The most common side effects of the drug are mild to moderate elevations (15.6\%) in liver enzymes, abdominal pain, nausea or vomiting, and headache (5). Albendazole-induced side effects such as alopecia and cytopenia are rare and reversible, providing that treatment is interrupted (6). All available cases reported in the English literature review searched in PubMed are summarized (Table 1). According to this summary, the ages of patients in nine cases, including ours, ranged from 9 to 74 years old, and only two of them were male. Although hair loss commonly develops in patients with 
long-term and/or high-dose albendazole use, complaints occurred in three patients within only 1 week or less of albendazole use and/ or after low-dose drug use. It should be borne in mind that hair loss may be accompanied by cytopenia, hepatotoxicity, or loss of all body hair. Irreversible hair loss has not been reported so far.

The first case of $\mathrm{AE}$ due to albendazole was recently reported. This case, compatible with $\mathrm{AE}$, appeared 2 weeks after treatment in a 74-year-old female patient using $800 \mathrm{mg} /$ day albendazole for 5 days due to positive Toxocara antibody serology. Unlike our cases, it was reported that hair loss was not only on the scalp but also across the body (6). There are only a few reported cases of alopecia, especially during treatment of hydatid cysts $(7,8)$. However, the diagnosis of some alopecia has not been reported (9). Taş et al. reported that an adult patient that received albendazole at a dose $15 \mathrm{mg} / \mathrm{kg} /$ day developed total loss of scalp and body hairs on the 2oth day of treatment (9). However, in their report, no biopsy was taken from the patient, and it was not ruled out whether the patient's diagnosis was alopecia universalis or AE. Hair loss in telogen effluvium (TE) usually occurs 2 to 4 months after drug use. In $\mathrm{AE}$, the occurrence of hair loss within the first 14 days after drug use is especially essential in the differential diagnosis from TE $(6,10,11)$. Based on his clinical history, we believe that this patient may have $\mathrm{AE}$.

In the patients in this study, $\mathrm{AE}, \mathrm{TE}$, alopecia incognito (AI), and androgenic alopecia (AGA) were considered in the differential diagnosis, respectively. In the histopathological examination for AI, in addition to perifollicular lymphocytic infiltration, exclamation hair and yellow dots were seen in trichoscopy. The diameter is different in hair shafts in AGA. AE was considered in our cases, based on the absence of findings such as hair shaft diameter variation, peripilar halo, perifollicular erythema, pigmentation, hemorrhages, black dots, and yellow dots. In a normal trichogram, $89 \%$ of the hair is expected in anagen, $10 \%$ in telogen, and $1 \%$ in the catagen phase (12). TE can be diagnosed when more than 15 to $25 \%$ of the hairs examined are in telogen. In AE, histopathological evaluation of a punch biopsy of the scalp will exhibit normal anagen-to-telogen ratios, which are less than 15\% telogen hair fol- licles (13). Accordingly, AE was considered in our patients.

$\mathrm{AE}$ is often triggered by antimitotic chemotherapeutic agents such as alkylating agents and antimetabolites (11). The primary effect of albendazole is to inhibit cellular microtubule polymerization binding to $\beta$-tubulin. Albendazole, which has a parasitic selective chemotherapeutic effect in this way, is more toxic for the infestation investigated here because it binds with much less affinity to mammalian $\beta$-tubulin (1). We believe that albendazole-induced alopecia may be the result of the higher affinity binding of human $\beta$-tubulin in some patients despite selective toxicity. Thus, like other chemotherapeutic drugs with antiproliferative effects, it can cause alopecia and cytopenia (14). Given the mechanism of action, it may be similar to drugs that disrupt microtubule polymerization, such as colchicine. It has been reported that cytopenia and $\mathrm{AE}$ are seen in acute intoxication of colchicine $(12,15)$. With side effects such as alopecia, cytopenia may also be associated with pharmacokinetic variations of albendazole. From this point of view, although it is not surprising that albendazole causes $\mathrm{AE}$, it is interesting that albendazole-induced TE continues to be reported. However, folic acid was reported as decreasing from 21 to $6.7 \mathrm{nmol} / \mathrm{l}$ in 3 weeks with albendazole treatment (2). That may be related to the mechanism of TE, in particular for long-term albendazole use. Although we have no evidence, albendazole may induce TE by partially suppressing biotinidase activity by hepatic toxicity, similar to isotretinoin and valproic acid (16).

In sudden-onset alopecia, drug-induced alopecia should be considered. For patients that develop hair loss after albendazole, we suggest that a hemogram and LFT be requested for concomitant cytopenia and hepatotoxicity, and that their folic acid level be checked. The speed and timing of hair loss will aid an accurate diagnosis. In order to consider possible pathogenesis mechanisms, we have presented our albendazole-induced AE cases together with all other cases.

\section{Acknowledgement}

We would like to thank the pathologist Ahmet Erkan Bilici.

\section{References}

1. Goodman LS, Brunton LL, Chabner B, Knollmann BC. Goodman \& Gilman's The pharmacological basis of therapeutics. 12th ed. New York: McGraw-Hill; 2011. Chapter 51. Chemotherapy of helminth infections; p. 1450.

2. Steiger U, Cotting J, Reichen J. Albendazole treatment of echinococcosis in humans: effects on microsomal metabolism and drug tolerance. Clin Pharmacol Ther. 1990;47:347-53.

3. Vildosola Gonzales H, Sanchez L, Espinoza R. [Albendazole for the treatment of hepatic and intra-abdominal hydatidosis]. Rev Gastroenterol Peru. 1989;9:1723. Spanish.

4. Mihmanli M, Idiz UO, Kaya C, Demir U, Bostanci O, Omeroglu S, et al. Current status of diagnosis and treatment of hepatic echinococcosis. World J Hepatol. 2016;8:1169.

5. Teggi A, Lastilla M, De Rosa F. Therapy of human hydatid disease with mebendazole and albendazole. Antimicrob Agents Chemother. 1993;37:1679-84.

6. Ghias MH, Amin BD, Kutner AJ. Albendazole-induced anagen effluvium. JAAD Case Rep. 2020;6:54-6.

7. Imamkuliev KD, Alekseev VG, Dovgalev AS, Avdiukhina TI. A case of alopecia in a patient with hydatid disease treated with Nemozole (albendazole). Med Parazitol (Mosk). 2013:48-50.

8. Tomas S, Montserrat M, Segarra M, Casademont J. Alopecia and albendazole. Enferm Infecc Microbiol Clin. 1993;11:113-4.

9. Tas A, Koklu S, Celik H. Loss of body hair as a side effect of albendazole. Wien Klin Wochenschr. 2012;124:220.

10. Hughes EC, Saleh D. Telogen effluvium. Treasure Island, FL: StatPearls Publishing; 2019.

11. Saleh D, Cook C. Anagen effluvium. Treasure Island, FL: StatPearls Publishing; 2019.

12. Bains A, Verma GK, Vedant D, Negi A. Anagen effluvium secondary to Gloriosa superba ingestion. Indian J Dermatol Venereol Leprol. 2016;82:677-80.

13. Kanwar AJ, Narang T. Anagen effluvium. Indian J Dermatol Venereol Leprol. 2013; 79:604-12.

14. Hanusova V, Skalova L, Kralova V, Matouskova P. Potential anti-cancer drugs commonly used for other indications. Current Cancer Drug Targets. 2015;15:35-52.

15. Alaygut D, Kilic SC, Kaya A, Oflaz MB, Bolat F, Cevit O, et al. Assessment of 17 pediatric cases with colchicine poisoning in a 2-year period. Pediatr Emerg Care. 2016;32:168-72.

16. Arslan M, Vurucu S, Balamtekin N, Unay B, Akin R, Kurt I, et al. The effects of biotin supplementation on serum and liver tissue biotinidase enzyme activity and alopecia in rats which were administrated to valproic acid. Brain Dev. 2009; 31:405-10.

17. Pilar Garcia-Muret M, Sitjas D, Tuneu L, de Moragas JMI. Telogen effluvium associated with albendazole therapy. Int J Dermatol. 1990;9:669-70.

18. Meneghelli UG, Martinelli AL, Bellucci AD, Villanova MG, Velludo ML, Magro J. Polycystic hydatid disease (Echinococcus vogeli). Treatment with albendazole. Ann Trop Med Parasitol. 1992;2:151-6.

19. Veraldi S, Francia C, La Vela V, Nazzaro G, Barbareschi M. Telogen effluvium after oral albendazole. Clin Exp Dermatol. 2012;5:565-7.

20. Riggan MAA, Perreault G, Wen A, Raco V, Vassallo S, Gerona R, et al. Case report: analytically confirmed severe albenzadole overdose presenting with alopecia and pancytopenia. Am J Trop Med Hyg. 2020;1:177-9. 